\title{
Sustainable and socially responsible business: doable reality or just a luxury? An exploratory study of the Bangladeshi manufacturing SMEs
}

\author{
Abstract: Drawing on the ISO 26000: 2010 - Guidance on Social Responsibility, this \\ study investigates the extent to which Bangladeshi manufacturing SMEs are \\ incorporating sustainability into their day-to-day business activities. The findings \\ reconfirm the existence of the so called 'attitude-behaviour' gap. The barriers that \\ hinder the sustainable engagement of SMEs include corruption, a weak regulatory \\ environment, inefficient or ill-suited government and external support, and a lack of \\ awareness of the environmental aspects of SR. In addition, this research reveals that \\ Bangladeshi manufacturing SMEs do, to a certain degree, implement sustainability; \\ only those few issues that suit the owner-managers' personal motives are addressed, \\ while some others are neglected. Finally, it has been found that the business type and \\ size, and the owner-managers' educational attainments have no significant influence \\ on the degree of adoption of sustainable and socially responsible business practices by \\ Bangladeshi manufacturing SMEs.
}

Keywords: small and medium-sized enterprises; SMEs; social responsibility; ISO 26000; ethics; sustainability; developing countries; Bangladesh.

\section{Introduction}

The concept of sustainability among small and medium-sized enterprises (SMEs) in developing countries is a topic discussed rarely in academic and non-academic literature. The overwhelming amount of research papers, articles, theories and case studies have mostly discussed the issue either from the perspective of large corporations or SMEs located in developed countries. Limited research has been done so far to shed light on the sustainability issues in SMEs based in developing and least developed countries (Demuijnck and Ngnodjom, 2013; Jamali et al., 2009; Tang and Tang, 2015). This partly stems from the nature of the concept of sustainability as a predominantly developed- country and large corporation-related phenomenon in its language and approach (Southwell, 2004; Murillo and Lozano, 2006; Tang et al., 2010). SMEs make up 90\% of businesses worldwide and create over 50\% of employment (Jenkins, 2004; Luetkenhorst, 2004; Raynard and Forstater, 2002), playing a significant role in the promotion of social and economic development. Moreover, the vast number of SMEs located in developing countries, and the significance of their accumulated contribution to the global economy justifies the need for further study to investigate the issue of sustainability from the perspective of SMEs in developing countries. This is also critically important since in these regions the stakes are so high in terms of poverty alleviation, sustainable employment opportunities, social and environmental challenges and the fight against corruption (Spence and Painter-Morland, 2010a).

Faced with these limitations in the extant literature, the main purpose of the current study is to investigate the extent to which manufacturing SMEs in Bangladesh (a low-income developing country in South Asia) are incorporating sustainability/social responsibility (SR) ${ }^{1}$ into their regular business activities. The study also unearths the key barriers or challenges SMEs face to operate responsibly in a socio-economic environment that instigates irresponsible business behaviour. Sustainable and socially responsible behaviour is critical in the context of Bangladeshi SMEs as they form a predominant part of the economy and have the potential to affect the society and the stakeholders in both positive and negative ways (Azmat, 2008). However, a major frustration for most policy researchers in Bangladesh is the virtual non-existence of research data on sustainability and related issues. So through this exploratory study, I aim to provide some empirical data. I decided to investigate this topic for two prime reasons. First, it is a product of a personal interest and passion 
for understanding how local enterprises can contribute to society and sustainable development. Second, no previous research has been done so far on sustainability in SMEs from a Bangladeshi perspective, which opened the opportunity to explore and execute a new research to shed light on the issue and provide some sort of information.

This paper responds to Spence and Painter-Morland's (2010a, p.333) call for the development of a tool suited to assess the meaningful involvement of SMEs in socially responsible and sustainable business activities. Drawing on the four key elements identified in ISO 26000 - namely, labour practices, the environment, consumer issues, and community involvement and development - and by employing a unique, realistic, and not hitherto used technique, a sustainability score was quantitatively calculated for the selected SMEs (details in the 'research methodology' section). Further, Willard's $(2005,2009)$ 'five stages of sustainability' model was utilised to reveal the level of implementation of sustainability in the surveyed SMEs. The first stage of this model is precompliance, in which companies do not follow any regulations. This is followed by: 
compliance, beyond compliance, integrated strategy (sustainability integrated into a company's strategy and culture), and purpose and passion (in which a company helps to build a better world). The remainder of the paper proceeds as follows: in the next section, to provide some conceptual understanding of the current study, a brief review of the literature on SR in SMEs based in developing countries is presented. The third section outlines the key methodological issues considered in this paper. The fourth and fifth sections report and discuss the research findings in detail, and the last section outlines the limitations of the study and discusses some of the policy and social implications of the research findings.

\section{Literature review}

\subsection{SR in developing-country SMEs: insights from the extant literature}

Owner-managers of SMEs in developing countries generally hold a positive attitude towards SR and consider it to be an important aspect of their business. In practice, this positive attitude is undermined by low levels of engagement as most owner-managers do not believe such activities to be commercially viable (Jeppesen et al., 2012; Yu and Bell, 2007). High costs, lack of human resources and knowledge (Ramasobana and Fatoki, 2014), lack of awareness (Demuijnck and Ngnodjom, 2013), and lack of training on sustainability (Vives, 2006) are cited as the most common problems that deter SME owner-managers from translating their positive attitude into action. This having been said, negative attitudes are not uncommon. The evidence shows that two factors namely, the owner-managers' perception of the importance of money (Au and Tse, 2001), and their selfishness (Bhutta et al., 2008) - are significantly associated with the low ethical standards and negative perception of SR found in developing countries.

In some developing countries, the perception of SR is affected by the specific cultural and religious context (Uygur, 2009; Perry et al., 2015). For example, in Sri Lanka, the Buddhist philosophy provides a fundamental basis for the understanding of SR and hence facilitates the engagement of SMEs in its implementation (Perry, 2013; Perry et al., 2015). In many other developing countries, SME owner-managers perceive SR as a form of philanthropy and consider it to be a religious duty; this has been identified in Africa (Amaeshi et al., 2006; Kivuitu et al., 2005) and in some South Asian countries (Azmat and Samaratunge, 2009). Other factors that motivate SMEs to undertake socially responsible practices include regulatory pressures (Roy et al., 2013), the owner-managers' personal values and passion for SR (Murillo and Lozano, 2006; Spence et al., 2011), financial motives (Tsoi, 2010), and a desire for differentiation (Jamali et al., 2009; Lin and Ho, 2011).

The owner-managers of SMEs in developing countries consider employee welfare and community development to be the two most important aspects of SR, and assign comparatively less importance to environmental issues (Demuijnck and Ngnodjom, 2013; Tsoi, 2010). In fact, many do not even consider the environment to be an issue and do not realise how their activities have an impact on it (Yu and Bell, 2007; Roy et al., 2013).

Also, it should be noted that the perception of SR in developing countries is greatly influenced by many other unique external factors, such as corruption, a poor socio-economic and regulatory environment, and lack of government support (Jamali et al., 2015; Panda and Dash, 2014). Thus, to understand how owner-managers make 
sense of the term SR, we must learn the circumstances under which they operate and the unique challenges and barriers they face whilst implementing SR (Jamali et al., 2009).

\subsection{SR and SMEs in Bangladesh}

SR has long been practiced in the businesses of Bangladesh and of other South Asian countries in the form of traditional philanthropic activities (Nasrullah and Rahim, 2014). These include donations to various charitable organisations, disadvantaged and poor people, religious and educational institutions, and hospitals (Mintoo, 2006; Miyan, 2011). Most SMEs in Bangladesh belong to the informal sector ${ }^{2}$, have minimal management structure and resources to address social and environmental issues, and are characterised by their small size, lack of professionalism, and low public visibility. These limitations often drive the owner-managers to think only about profit maximisation, rather than consider the triple bottom line of profit, planet, and people in doing business (Azmat, 2008; Azmat and Samaratunge, 2009).

The Ministry of Industries' (2005) Policy Strategies for Small and Medium Enterprises (SME) Development in Bangladesh is the only existing such policy in Bangladesh. It emphasises several important aspects of SME development, such as finance, technological support, tax rebate, and the identification of booster sectors, but does not sufficiently stress the issue of sustainability. The National Sustainable Development Strategy (NSDS, 2013) describes the challenges faced by the government in ensuring sustainability in the industrial sector and clearly admits that the latter does not yet attach much importance to SR and sustainability issues. However, based on the fundamentals of the earlier 2005 SME policy strategy, the government is planning to prepare a new one in 2015-2016 (Begum, 2013); it is hoped that this new policy will provide SMEs with enough guidance to implement sustainability.

The most recent National Industrial Policy (2010) does provide more adequate support for the flourishing private sector initiatives, as described in Article 13. The policy states that, by means of tax and duty exemptions, the government plans to incentivise industries and SMEs to adopt environmentally sound manufacturing processes and practices. In order to promote investment in projects designed to reduce the emission of greenhouse gases under the Kyoto protocol's clean development mechanism (CDM), the government will take essential actions through the board of investment (BOI). In addition, the policy states that the government will provide facilities for the setting up of a waste recycling industry. Entrepreneurs will be encouraged to vigorously pursue the 3Rs (reduce, reuse and recycle) when setting up and running their businesses. Furthermore, the policy also identifies SMEs as a key engine of economic growth. Particular emphasis is also placed on the organic pesticide industry in order to protect the natural environment through the preservation of useful insects, soil microbes, and aquatic life (Hasan and Islam, 2015).

\subsubsection{Existing research on SMEs}

The extant SR/sustainability literature in the context of Bangladesh is biased towards studying the CSR reporting or disclosures of multinational companies (MNC), private commercial banks, and insurance companies (e.g. Belal and Momin, 2009; Momin and Hossain, 2011; Islam and Deegan, 2008; Khan et al., 2013; Belal and Cooper, 2011; Rouf, 2011). To date, very little research (if any) has been done to understand how SMEs 
themselves understand the concept of SR and the extent to which they incorporate sustainability. As mentioned earlier, in Bangladesh and in many other developing countries, SMEs form a large part of the informal sector; yet, their contribution towards alleviating poverty and boosting economic growth remains critical (Azmat, 2008). The Bangladesh Small and Cottage Industries Corporation's (BSCIC, 2013) ${ }^{3}$ statistics show that, in Bangladesh, there are currently 933,991 small and cottage industries, employing more than 3.6 million people and contributing around $19.54 \%$ of the national GDP. Thus, the cumulative social and environmental impact of this sector is massive and it is therefore paramount that it operates sustainably.

\subsubsection{Definition of SMEs in Bangladesh}

In Bangladesh, there is no single agreed upon definition of SME. Different versions of the National Industrial Policy and other government reports define SMEs based on different criteria. This issue was dealt with in the recent National Industrial Policy (2010), which is the only (and latest) paper to provide a common definition of manufacturing SMEs to be used by all relevant authorities. This is used as a benchmark to define and identify manufacturing SMEs in Bangladesh; these are the focus of the current study, which advocates the adoption of a definition of SME based on employment, rather than on asset turnover or on both (for information on the latter is extremely difficult to obtain). According to this policy, manufacturing SMEs are SMEs that employ between 25 and 250 workers.

\section{Research methodology}

The sample companies were selected from a list of clusters provided by the SME Foundation (Ministry of Industry, Government of Bangladesh). This list, published in March 2013, is the most comprehensive and up-to-date database of all manufacturing SMEs in Bangladesh. It contains basic information on the location, postal address, sector and employment of 177 SME clusters in Bangladesh. Altogether, the list identifies 69,902 enterprises in those clusters [SME Foundation, (2013), p.7].

In the first phase, a total of 110 companies were identified and approached for the survey. These are all based in four zones of the Dhaka district - namely, Khilkhet, Jatrabari, Hazaribagh, and Chakbazar. The sampling techniques were both purposive and sequential (multiphase) [Adams et al., (2007), p.89; Creswell, (2009), p.183]. Purposive sampling involves a selection process based on specialist knowledge or specific criteria [Walliman, (2006), p.79]. Accordingly, a variety of industries were included to make the sample representative of the entire population. In a sequential sampling scheme, the researcher is allowed to reiterate the sampling process more than once [Adams et al., 2007, p.89]. The researcher identifies an initial sample and obtains information on it; the researcher then repeats the sampling process (on the initial sample) based upon a different purpose [Creswell, (2009), p.183]. Similarly, in this research, the participants for the second phase (i.e., the semi-structured interviews) were recruited during the first phase survey, in which all participants were asked to take part in the interviews. A total of 13 owner-managers agreed to do so. 


\subsection{Data collection}

Two data collection techniques - namely, a self-administered (paper-based) questionnaire survey and semi-structured interviews - were sequentially employed. In the first phase, the sustainability/SR score and SR implementation level of each selected SME were calculated based on the four key elements of SR addressed by ISO $26000^{4}$. This guidance publication had been selected for two main reasons; first, it is the only one that provides comprehensive guidance on SR and sustainability to date (Perera, 2008; Ávila et al., 2013) and, second, the Bangladesh Bank (the central bank of Bangladesh) and the High Commission of Canada in Bangladesh had extensively promoted ISO 26000 in the private sector during 2013-2014 (Islam et al., 2013). It was therefore assumed that the local business communities would be familiar with its contents.

\subsubsection{First phase (questionnaire survey)}

The questionnaire was divided into five main sections in accordance with the research aims (see Appendix). The first two sections gathered general information on the respondents and their businesses. The third section was more descriptive and was designed to gage the extent to which SMEs are incorporating SR in their regular business activities. In this section, the participants were asked to mention whether they were following (or maintaining) the various elements of SR described in ISO 26000. However, rather than just directly listing those elements in the questionnaire, I significantly adapted these elements into questions understandable by the participants. Other questions, culturally relevant and meaningful for Bangladeshi (manufacturing) SME owner-managers but not part of the ISO 26000 Guidance, were also included. For example, participants were asked whether they maintained their generators properly and efficiently. Due to power failures being a common occurrence in Bangladesh, generators are commonly used to ensure a back-up supply of electricity.

Finally, the fourth and fifth sections addressed participant perceptions of SR and of the drivers and barriers pertaining to their engagement in SR practices. To understand the owner-managers' perceptions of SR, as recommended by Islam et al. (2013, p.34), the fifth section, in particular, asked two specific hypothetical questions. At the end of the questionnaire, all participants were asked whether they would be willing to take part in face-to-face interviews during the second phase of the research.

A total of 110 printed questionnaires were distributed, 71 of which were returned. Not all of these, however, had been completely filled out. Several missing values were addressed and, after careful sorting, only 59 questionnaires were included in the final analysis.

\subsubsection{Second phase (semi-structured interviews)}

Once the completed survey questionnaires had been thoroughly checked, 13 ownermanagers were found to have made themselves available for the in-depth semi-structured interviews; of these, only seven could be eventually contacted. Considering that most SMEs are constantly subject to time pressures ( $\mathrm{Yu}$ and Bell, 2007), the duration of each interview, with one exception that lasted about 80 minutes, was generally kept at under 60 minutes. The interview questions were organised into five overarching categories: 
- company descriptions and owner-manager views on SR certification and standardisation (e.g., ISO standards)

- company interpretations of the implications of SR

- reasons for owner-manager engagement in SR and related activities; main drivers and motivating factors

- the greatest obstacles to the adoption of sustainable and socially responsible business strategies in the Bangladeshi context

- government policies and other advocacy organisations in support of the sustainable operation of SMEs.

\subsection{Data analysis - questionnaire survey (first phase)}

This study does not intend to make any generalisations about Bangladeshi manufacturing SMEs, but is instead aimed at taking a more interpretative position in gaining a better understanding of SME perceptions of SR and of the barriers and challenges faced by these companies. This approach is similar to that adopted by Vives et al. (2005) in their study of SR in eight Latin American SMEs. Therefore, the data were analysed using descriptive statistical tools; these provided a good insight into the current conditions of Bangladeshi manufacturing SMEs in the field of SR. The Stata statistical software and Microsoft Excel were used for the data analysis and for illustration purposes. The initial step taken to organise the data in a usable manner involved the definition of the variables; this was followed by the assignation of numbers to the different categorical answers and their entry into an Excel spreadsheet. The statistical measurements used to analyse the data were frequency of occurrence and cross tabulation. In cases in which survey data consist of nominal and/or ordinal values, the measurement of frequency of occurrence is more appropriate than traditional ones such as mean and standard deviation (Pallant, 2007). However, multiple regression analysis was also used to determine whether company size and type, and owner-manager educational level have any effect on the degree of SR implementation. To facilitate the regression analysis, a few dummy variables were created and certain modifications were made to the controlled ones (Singh, 2007).

\subsubsection{Calculation of sustainability/SR score}

The sustainability/SR scores of each selected SME were calculated by using a simple and unique measurement technique specifically designed for this study. In section three of the questionnaire, each participant was asked whether his/her business was dealing with different elements of SR, such as labour issues, environment, consumer issues, and community involvement and development. Each positive answer was allocated a weight of 1 and then the total number of positive answers was divided by the number of issues asked. However, any issue deemed not to be applicable to his/her business by the participant was taken out of the calculation. Table 1 illustrates the calculation of the sustainability/SR scores for one of the participating companies: 
Table 1

Calculation of sustainability/SR score

\begin{tabular}{|c|c|c|c|}
\hline Labour practices & The environment & Consumer issues & $\begin{array}{l}\text { Community } \\
\text { involvement and } \\
\text { development }\end{array}$ \\
\hline $\begin{array}{l}\text { Total issues asked/ } \\
\text { mentioned }=8\end{array}$ & $\begin{array}{l}\text { Total issues asked/ } \\
\text { mentioned }=18\end{array}$ & $\begin{array}{l}\text { Total issues asked/ } \\
\text { mentioned }=5\end{array}$ & $\begin{array}{l}\text { Total issues asked/ } \\
\text { mentioned }=6\end{array}$ \\
\hline $\begin{array}{l}\text { Number of positive answers }= \\
6\end{array}$ & $\begin{array}{l}\text { Number of positive } \\
\text { answers }=8\end{array}$ & $\begin{array}{l}\text { Number of positive } \\
\text { answers }=3\end{array}$ & $\begin{array}{l}\text { Number of positive } \\
\text { answers }=3\end{array}$ \\
\hline Not applicable $=1$ & Not applicable $=4$ & Not applicable $=0$ & Not applicable $=0$ \\
\hline $\begin{array}{l}\text { Score }=6 / 8-1=0.86 \\
(86 \%)\end{array}$ & $\begin{array}{l}\mathrm{re}=8 / 18-4=0.57 \\
\%)\end{array}$ & $\begin{array}{l}\text { Score }=3 / 5=0.60 \\
(60 \%)\end{array}$ & $\begin{array}{l}\text { ore }=3 / 6=0.50 \\
0 \%)\end{array}$ \\
\hline
\end{tabular}

So the average sustainability/SR score obtained by that particular business was $(0.86+$ $0.57+0.60+0.50) / 4=0.63$ (or $63 \%$ ). Note: throughout this paper, the average sustainability/SR scores are reported as percentages.

\subsubsection{Calculation of average level of SR implementation}

The SR implementation levels of Bangladeshi manufacturing SMEs were measured on a zero- to four-scale, with zero meaning 'no implementation' and four meaning 'full integration of sustainability and SR into company culture'. These SR implementation levels were established based on the five stages of sustainability suggested by Willard $(2005,2009,2012)$. However, some modifications were made to make them more relevant to the context of Bangladeshi manufacturing SMEs.

In order to calculate the SR implementation levels, scores ranging from 0 to 4 were awarded according to the level of SR achievement; for example, if a firm had a written SR/sustainability policy but had not yet implemented it, it scored 1 point. Table 2 shows the calculation of the average SR implementation level of one of the participating firms 5 .

Thus, the average level implementation for that particular company was 1.67; it could be placed between level 1 and level 2 in terms of its SR implementation.

\subsection{Data analysis - in-depth interviews (second phase)}

The interviews were manually transcribed, anonymised and analysed in Bangla (the national language of Bangladesh); later, the Bangla quotations were transliterated into English during the writing up process. The relevant quotations were selected and elaborated into a fluent text to make them more readable. The interview questions were generated based on the key objectives of this research. All transcripts were scrutinised thoroughly and analysed for valid, meaningful and relevant themes. Due to the emphasis placed on systematic, consistent techniques that reduce data into manageable descriptive forms (Hsieh and Shannon, 2005), content analysis was chosen as the analytic technique. Fitting with the research questions, content analysis incorporates both inductive and deductive methods, whereby pre-determined categories (or issues) are used to initially guide analysis, with additional categories emerging through the study (Altheide, 1987; Merriam, 2014). 
Community involvement

and development

Level 1 Level 2 (fractional Level 3 (full

Level 3 (full

Level 4 (beyond

implementation
im

$N / A$

paper)

$-1$

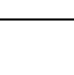

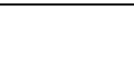

counted

Labour practices

Total score

5 out of 12 (as one was opted out)

Average level of $\mathrm{SR}$ implementation $=5 / 3=1.67$ 


\begin{tabular}{|c|c|c|c|c|c|}
\hline Position in the business & & & Size of business & & \\
\hline Owner & 25 & $(42 \%)$ & Small & 47 & $(79.66 \%)$ \\
\hline Partner & 8 & $(14 \%)$ & Medium & 12 & $(20.34 \%)$ \\
\hline Manager & 22 & $(37 \%)$ & Main market (geographical scale) & & \\
\hline Other & 4 & $(37 \%)$ & Local (community based) & 24 & $(41 \%)$ \\
\hline Gender & & & National & 19 & $(32 \%)$ \\
\hline Male & 56 & $(95 \%)$ & Global (export) & 16 & $(27 \%)$ \\
\hline Female & 3 & $(5 \%)$ & Sector & & \\
\hline Age of respondents & & & Knitwear and ready-made garments & 24 & $(41 \%)$ \\
\hline Average: & 39.77 & & Plastics and other synthetics & 12 & $(20 \%)$ \\
\hline Std. dev.: & 11.24 & & Leather making and leather goods & 6 & $(10 \%)$ \\
\hline Minimum age: & 23 & & Light engineering and metal working & 8 & $(14 \%)$ \\
\hline Maximum age: & 60 & & Handloom and specialised textiles & 6 & $(10 \%)$ \\
\hline Highest level of education completed & & & Handicraft & 3 & $(5 \%)$ \\
\hline Primary & 4 & $(7 \%)$ & International or national certifications on SR/sustainability & & \\
\hline Secondary & 6 & $(10 \%)$ & Yes & 16 & $(27 \%)$ \\
\hline Higher secondary & 13 & $(22 \%)$ & No & 43 & $(73 \%)$ \\
\hline Bachelor's & 27 & $(46 \%)$ & Years in operation & & \\
\hline Master’s & 9 & $(15 \%)$ & Average: & 11.90 & \\
\hline Other & 0 & $(0 \%)$ & Std. dev.: & 7.95 & \\
\hline With degree & 36 & $(61.02 \%)$ & Minimum: & 1 & \\
\hline Without degree & 23 & $(38.98 \%)$ & Maximum: & 30 & \\
\hline
\end{tabular}




\section{Findings}

\subsection{Overview of the sample firms and respondents}

In total, 59 usable responses covering six sectors were received from a sample population of 110 manufacturing SMEs, giving a response rate of 53.60\%. The in-depth interviews were conducted with seven SME owner-managers identified from the initial sample. The majority of respondents were business owners and/or managers. This was an advantage, as their values and perceptions have a great influence on business decisions, including those pertaining to SR (Isaksson et al., 2010), and their understanding provided a good insight into business culture, practices and goals (Jenkins, 2004; Spence and Rutherfoord, 2003). Interestingly, many respondents had a degree-level education $(61.02 \%)$, which provided an opportunity to see whether education attainment levels have any effect on the extent to which the owner-managers of Bangladeshi manufacturing SMEs engage in sustainable and socially responsible business practices.

In regard to business size, $79.66 \%$ were small enterprises (25-99 employees) and 20.34\% were medium ones (100-250 employees), which represents the current situation of manufacturing SMEs in Bangladesh (Ahmed and Rahman, 2012). The average time the SMEs had existed was 11.90 years. Although survey data were collected from SMEs operating in 6 sectors (see Table 5), the majority of the responding SMEs were related to the apparel industry (41\%), which contributes $16 \%$ to Bangladesh's GDP and 79.63\% to total export earnings (BBS, 2012; BGMEA, 2013). Of the sample SMEs, 24 reported to be local, 19 had expanded to the national level, and 16 exported their goods and/or services. Finally, the interviewed SMEs represented the three sectors of apparel, plastic products, and leather goods. Four out of seven had adopted particular SR standards, and participants were all either owners or managers except one who simultaneously maintained accounts and managed. Tables 3 and 4 present a brief summary of the sample and participants.

Table 4 The interview respondents

\begin{tabular}{|c|c|c|c|c|}
\hline Notation & Position & $\begin{array}{c}\text { Firm } \\
\text { dimension }\end{array}$ & Main products (sector) & $\begin{array}{r}\text { Adopted } \\
\text { standards }\end{array}$ \\
\hline RI & Owner & Small & Plastic doors (plastics and other synthetics) & ISO 9001 \\
\hline MA & Manager & Small & Garment labels (knitwear and RMG) & $\begin{array}{l}\text { ISO 9001, } \\
\text { SA } 8000\end{array}$ \\
\hline SA & Manager & Small & Fabric for gents shirt (knitwear and RMG) & None \\
\hline MJ & Owner & Medium & $\begin{array}{l}\text { Leather bags, shoes, wallets etc. (leather } \\
\text { making and leather goods) }\end{array}$ & ISO 14001 \\
\hline $\mathrm{KH}$ & Owner & Small & $\begin{array}{l}\text { Plastic pipes and fittings (plastics and } \\
\text { other synthetics) }\end{array}$ & None \\
\hline KT & $\begin{array}{l}\text { Manager/ } \\
\text { accountant }\end{array}$ & Medium & Polo T-shirts (knitwear and RMG) & ISO 14001 \\
\hline TI & Owner & Small & $\begin{array}{l}\text { Garment fabrics, buttons, chains } \\
\text { (knitwear and RMG) }\end{array}$ & None \\
\hline
\end{tabular}




\subsection{Perceptions of SR}

In the survey questionnaire, the majority of respondents (41\%) indicated (Appendix: Section 5, question 1) that a responsible business does not only donate money to charitable organisations but engages in many more internal and external aspects of SR. Only 7\% of the respondents associated SR with charitable activities such as donating money to hospitals and religious or educational institutions. This clearly shows that the owner-managers of the selected SMEs have a very high level of understanding of the concept of CSR or SR. Further, the majority of the owner-managers consider consumer issues and fair operating practices to be the most relevant elements of SR outlined in ISO 26000 (25\% and 20\% respectively). Finally, all respondents (except one) replied 'no' (which is a positive response) to the two hypothetical questions asked in the survey questionnaire. By taking the cultural context into account, these questions were asked to determine whether Bangladeshi owner-managers are capable of correctly recognising SR in two (possible) practical situations (see question nos. 3 and 4 in Section 5 of Appendix). The answers to these questions confirm that Bangladeshi SME owner-managers do have a very clear idea of what SR implies.

However, an apparent contradiction in relation to perceptions of SR emerges between the survey findings and the interview outcomes. In exploring the interviewed owner-managers' perceptions and level of understanding of the concept of SR, a broad picture characterised by some common negative elements has emerged. All the owner- managers interviewed acknowledged the fact that $\mathrm{SR}$ is an essential aspect of any business, be it small or large. At the same time, most of them expressed their frustration regarding the implementation of SR in Bangladesh. For example, one of the owner- managers said:

"SR is an important element of doing business in all countries and for all types of business. But how many businesses maintain these things in Bangladesh? Everyone is devoted to making as much money as possible, by hook or by crook. The government officials who work in the regulatory institutions are all corrupt and sell certificates related to labour standards, safety in the premises and so on. Nobody cares about the society and environment. So, in reality, there is no SR in Bangladesh.” (MJ, owner of a leather factory)

Surprisingly, some SME owner-managers do not consider SR to be part of their duties and explicitly expressed being only concerned with maximising profits and surviving in the market. One of them said:

"To be honest with you, we never talk about these issues; neither do we get time for such things. Buyers order goods from us, the only thing they ask for is the cheapest price so that they can make more profit, and we try our best to cut corners in every possible way to stay in the competition." (RI, owner of a plastic door making factory)

Another owner said:

"We are not selling or producing anything illegal, we are just doing everything that is necessary to survive in the competition. If we paid proper salaries, maintained all these things that you (indicating the researcher) are talking about, then we simply could not survive. If factories can get certificates without doing these things, then why should they even bother?" $(\mathrm{KH}$, owner of a plastic pipe making factory) 
On the same issue, another manager said:

"If you use Europe-America (referring to developed countries) as the benchmark, then people will not agree. We live in Bangladesh and, here, these things are not possible." (SA, manager of an apparel factory)

Overall, all the owner-managers interviewed related SR to philanthropic activities (i.e. donating money for charity purpose), which was inconsistent with the survey findings. None of the interviewed owner-managers was aware of the ISO 26000 Guidance, but all seemed to agree with its contents when they were briefly explained by the researcher. This suggests that SR principles may be widespread even without an explicit awareness of the related standards. Further, from the perspective of Bangladeshi SMEs, labour and consumer issues were seen as the most important aspects of SR. One manager said:

"Labour issues are very important; we have to satisfy them (the workers) as we operate in a labour intensive sector. After that, the consumer issue is important, as they are the ones who buy from us. The environment and other issues are difficult to understand and maintain for a small business like ours." (TI, owner of a small garment accessories supplier)

Finally, the owner-managers, in general, agreed that SR can increase profits in the long run, but, at the same time, expressed their worries about the initial implementation costs. For example, one owner interviewed said:

"I am not entirely convinced of how all these (SR elements) can add to the final bottom line, but I can roughly sense that they would benefit business in the long run. Initially it would be very expensive and I would have to change the whole system of my business!." (MJ, owner of a leather factory)

\subsection{Driving factors of sustainable and socially responsible practices}

Inconclusive results were found with regard to the main drivers or motivating factors for the engagement in SR. The sample manufacturing SMEs engage in socially responsible business practices mainly to meet customer expectations (37\%), to improve their overall business reputation $(18 \%)$, for religious and personal beliefs (30\%), and (to some extent) to comply with domestic and international laws (11\%). On the other hand, stakeholder pressure (e.g., that applied by international buyers, the government, NGOs, advocacy organisations, etc.) is not recognised as a reason to implement SR.

Only two motivating factors were identified from the interviews. The majority of owner-managers highlighted ties and integration with the local community as main drivers of SR activities. Alongside these, religious beliefs and personal values were considered fundamental by almost everyone interviewed. Interestingly, fulfilling government and/or local laws regarding SR and meeting customer expectations were not mentioned by any of the owner-managers interviewed, which contradicts the main survey findings. All in all, it emerges that SMEs in Bangladesh tend to engage in SR related activities in the form of philanthropy. In so doing, they strive to maintain their close relationships with their local communities and create positive public perceptions. SME owner-managers do this primarily from a religious (Islamic) point of view and then from a general ethical (personal beliefs and passion) perspective. One manager said:

"We are Muslims and it is our religious duty to donate money that we earn by doing jobs or running businesses. So I do most things related to SR from my 
religious beliefs. And I always try my best not to exploit the labourers who work for me." (MJ, owner of a leather factory)

Whilst religious beliefs and enhancing business reputation were frequently cited by the ownermanagers interviewed as salient factors motivating the involvement in SR of the Bangladeshi manufacturing SMEs presented in this paper, none mentioned government and local laws as drivers of SR engagement. This is because they do not think such laws have any influence on the implementation of SR. One manager clearly said:

"You can get certificates, even ISO ones, if you bribe the issuing authorities, and everyone is aware of this. So I never worry about such laws. I do things that are good for my business and try my best to maintain a good working environment inside my factory. So, SR in my factory is only driven by my personal passion." (SA, manager of an Apparel factory)

\subsection{Barriers to the engagement in socially responsible/sustainable activities}

The Bangladeshi manufacturing SMEs recognised that the main barrier hindering the implementation of SR is the lack of government support. The second most common perceived barrier is the lack of understanding of the issue and of its possible benefits (15\%), which is also related to the fact that SMEs in developing countries do not consider SR to be an investment beneficial to society and also to the business in the long run (Yu and Bell, 2007; Ramasobana and Fatoki, 2014). Other important barriers identified by the surveyed SMEs are the perception that SR brings no immediate financial gain, and lack of efficient institutions to assist and implement SR (14\% and $13 \%$, respectively). Rather surprisingly, human resource limitations, regulatory authority corruption, and lack of finance were not reported as obstacles by most firms.

Conversely, the interviews revealed that the main barriers hindering the implementation of SR are corruption, lack of awareness and perception, lack of financial resources, and lack of external support.

\subsubsection{Corruption}

The first issue mentioned repeatedly by the interviewed owner-managers as an obstacle to the implementation of SR in Bangladesh was corruption. According to Transparency International (2013), Bangladesh belongs to the group of most corrupt countries; hence, this is a major problem for SMEs. All the owner-managers had experienced dealing with highly corrupt regulatory authorities and government officials. In particular, the systematic paying of bribes to government officers (to obtain certificates and clearances) and to customs people (to secure the release of imported goods) is a common practice in Bangladesh. One manager said that, "it would take ages to clear customs if we didn't pay the expected 'supplement' to get the raw materials imported from China” (KT, Knitwear and RMG). SMEs are paying bribes to obtain SR related certificates, as this is cheaper than implementing the SR measures themselves. They are constrained by the general institutional environment and are motivated to take the easier and cheaper option. One manager sadly said:

\footnotetext{
"If you want to remain honest, you have to accept that you will lose business from time to time. For example, if we installed an ETP (Effluent Treatment Plant) in a proper way and did everything as per the government requirements, we would still need to bribe the officials to get clearance! So we are forced to
} 
take the alternative route.” (KT, manager/accountant of a polo t-shirt manufacturer)

Interestingly, it was generally observed that none of the interviewees judged themselves to be in any respect responsible for this situation. It is indeed quite clear that it would be very difficult to combat the widespread social phenomenon of corruption in Bangladesh, but none of the ownermanagers mentioned also being part of this environment, and being able to play a vital role in overcoming these issues [a similar behaviour were identified by Demuijnck and Ngnodjom (2013) in their study of Cameroonian SMEs].

\subsubsection{Misconceptions and lack of awareness}

Although the owner-managers generally recognise the environmental and social impact of manufacturing SMEs in Bangladesh, most of them have little knowledge of the actual effects. In the interviews, most owner-managers considered their environmental impact to be very small. Many manufacturing SMEs even saw environmental issues as being unrelated to them ${ }^{6}$. In contradiction to the survey findings, during the interviews, it emerged how some managers still held old fashioned views of SR, perceiving its scope, for a company, as being limited to making a profit and paying salaries and taxes. One owner said:

"Rural women in this country have no education and no jobs; they would be working as housekeepers or begging on the streets had we not given them a job. My factory employs more than 50 women in the sewing section and they all are earning money that they could not earn elsewhere. So we are helping them and they are happy with whatever they are earning. We are not exploiting them by paying less, we are indeed helping them; this is SR!.” (TI, owner of a garment accessories supplying factory)

The owner-managers also are unaware of all the local environmental and other SR related laws, which suggests that both the government and the media are ineffective in disseminating the relevant information to local SMEs.

Another significant issue related to low or negative perceptions of SR is that the SME ownermanagers are still sceptical of the widespread assumption that the economic benefits linked to the adoption of a formal approach to sustainable management (or of environment friendly technology) would generally outweigh the related costs. In fact, a few owner-managers expressed their concern of SR related issues being too complicated to implement and measure. They saw the advantages gained from such activities, such as the reduction of environmental/social risks and the enhancement of employee motivation, as intangible assets quite disconnected from any enhancement of economic profits or market opportunities. The link between these intangible assets (as the owner-managers perceive them) and the ultimate financial bottom line (i.e., profit maximisation) is too complex for them to understand. Altogether, it was noticed that most SME owner-managers in Bangladesh are short-term orientated and profit-driven, which makes their reluctance to take any step to embark on sustainable activities quite understandable, as the benefits do not appear to them to match their major concern of maximising wealth. However, on this particular point, the owner-managers seem to contradict their own interpretation of the benefits of SR; during the interviews, many of them mentioned that they saw SR as a necessity which could lead to profit maximisation and help in building positive public perceptions. 


\subsubsection{The lack of financial resources and external support}

The lack of financial resources has already been identified as an inherent disadvantage for most SMEs operating in developing countries (Yu and Bell, 2007). Although the survey data indicated that lack of finance was not a major concern for SMEs with regard to their implementation of SR, the interviews revealed it as being, indeed, a great obstacle to the adoption of sustainable technology. Three of the seven owner-managers interviewed clearly mentioned that the certification and implementation of formal management standards such as ISO $9001^{7}$ and ISO $14001^{8}$ had been a burden on them. One manager said:

"We had to pay twice for such standards, first we paid the costs associated with the implementation process and then we paid for the ongoing maintenance. Eventually, we settled for an easier option (bribing officials to renew certificates) and you (indicating the researcher) can ask anyone; I am sure they did the same." (MJ, owner of a leather factory)

One fact is clear: due to some of their inherent characteristics, SMEs cannot overcome the difficulties related to implementing SR on their own. Unlike larger corporations, SMEs need the external support of NGOs, banks, advocacy organisations and the government to operate sustainably and contribute to overall sustainable development. However, as this research revealed, the external bodies, including governmental agencies and banks, largely fail to connect with this group. Most of the interviewed owner-managers clearly said that they were tired of the complex bureaucratic procedure involved in getting loans from commercial or government banks. One manager said:

"Don't ask about bank loans, it's a nightmare - the banks are sitting on heaps of cash, but the sad part is that we don't get any! Bank loans are for companies that are doing well and have high turnovers. We don't get anything without 'lobbying' even though we are struggling for survival and are badly in need of banking support to buy machinery and treatment plants." (MA, manager of a labelling factory)

Furthermore, the lack of sector specific support and of training and consultancies was mentioned by almost everyone interviewed. Although the interviewed owner-managers praised several workshop and training initiatives taken by the BSCIC, at the same time, they noted that most of these focus on issues that are unrelated to SR. None of the interviewed were aware of the latest National Industrial Policy (2010) or of the support facilities outlined therein. Overall, it would seem that the government and other regulatory authorities are very reluctant to realise that SMEs regularly lack the resources necessary to interpret and effectively adopt the increasingly strict and complicated regulations. Under such circumstances, owner-managers look for easier alternatives, such as bribing the issuing authorities and producing false SR related documents. Last, but not least, comes the lack of financial support; as discussed previously, most banks are unwilling to give loans to SMEs due to the latter's small economic scale and poor credit record. Therefore, most SME owner-managers feel that, on their own, they are unable to meet the expenses and, consequently, they move away from sustainable business activities. 


\subsection{Sustainability/SR scores and SR implementation levels of Bangladeshi manufacturing SMEs}

The survey data revealed that the sustainability/SR score ${ }^{9}$ of sample manufacturing SMEs is very high (80.48\%). However, an apparent contradiction is found between the average sustainability/SR score and the average level of SR implementation ${ }^{10}$, which is only 2.16 (see Table 5). So it could be said that although the surveyed owner-managers reported that they are maintaining or following different elements of SR outlined in ISO 26000, in terms of actual implementation, they seem to disagree with their own answers provided in Section 3 of the questionnaire (see Appendix). Table 5 shows the sector specific statistics based on the survey. It has been found that the "handloom and specialised textiles' sector has the highest level of SR implementation (2.58) while 'plastics and other synthetics' sector has the lowest (1.77). The average SR implementation level is more or less the same for all other sectors. 'Plastics and other synthetics' sector also has the lowest sustainability/SR score (73.65\%) whilst all other sectors scored similarly (between 80 to $85 \%$ ).

Further, Table 6 shows that environmental aspects obtain the lowest SR/sustainability score $(69.54 \%)$ followed by the issues related to community involvement and development $(74.42 \%)$. Almost similarly, the SR implementation level of environmental issues is found to be second lowest (1.98) while issues related to community involvement and development obtains the lowest implementation level (1.81). Consumer and labour issues scored highly in terms of both average SR/sustainability score and SR implementation level.

Table 5 Average SR implementation level and sustainability/SR score

\begin{tabular}{|c|c|c|c|c|c|c|c|c|c|c|}
\hline \multirow[t]{2}{*}{ Sector } & of $\mathrm{SMF \textrm {s }}$ implement & $\begin{array}{l}\text { Number } \\
\text { dov }\end{array}$ & $\begin{array}{l}\text { erage } S \\
\text { in Max } \\
\text { leve }\end{array}$ & iability/ & $\begin{array}{c}f \\
S \rho V \\
S R\end{array}$ & $\begin{array}{l}\text { Average } \\
\text { Min } \\
\text { score }\end{array}$ & \multicolumn{3}{|c|}{ Std. } & $\operatorname{Max}$ \\
\hline & $\begin{array}{l}\text { Knitwear } \\
\text { and RMG }\end{array}$ & 24 & 2.19 & 0.93 & 0 & 4 & 80.41 & 15.6640 & & 100 \\
\hline & $\begin{array}{l}\text { Plastics and } \\
\text { other synthetics }\end{array}$ & 12 & 1.77 & 0.97 & 0.50 & 3.75 & 73.65 & 29.74 & 0 & 100 \\
\hline & $\begin{array}{l}\text { Leather making } \\
\text { and leather goods }\end{array}$ & 6 & 2.20 & 1.54 & 0 & 4 & 83.42 & \multicolumn{2}{|c|}{24.2537 .50} & 100 \\
\hline & $\begin{array}{l}\text { Light engineering } \\
\text { and metal working }\end{array}$ & 8 & 2.24 & 0.88 & 1 & 3.50 & 82.75 & \multicolumn{2}{|l|}{15.5051} & 100 \\
\hline & $\begin{array}{l}\text { Handloom and } \\
\text { specialised } \\
\text { textiles }\end{array}$ & 6 & 2.58 & 1.02 & 1 & 4 & 85.92 & \multicolumn{2}{|c|}{13.8562 .50} & 100 \\
\hline & Handicraft & 3 & 2.33 & 0.58 & 2 & 3 & 85.50 & \multicolumn{2}{|c|}{12.6576 .75} & 100 \\
\hline & Total & 59 & 2.16 & 0.993 & 0 & 4 & 80.48 & 19.56 & 0 & 100 \\
\hline
\end{tabular}


Table 6

Implementation level and score of each individual SR issues

\begin{tabular}{lcc}
\hline SR/sustainability issues & Average SR/sustainability score & Average SR implementation level \\
\hline Labour practices & 88.92 & 2.28 \\
The environment & 69.54 & 1.98 \\
Consumer issues & 90.88 & 2.44 \\
Community involvement & 74.42 & 1.81 \\
and development & & \\
\hline
\end{tabular}

4.6 Influence of business size, type and owner-managers' educational level on the SR implementation levels and sustainability/SR scores

Cross tabulations and multiple regression analysis were run to find whether the owner- managers' educational level, business type and size have any impact on the SR implementation level and sustainability/SR score of the manufacturing SMEs in Bangladesh. Tables 7, 8 and 9 show the detailed results.

Table 7 Results from the cross-tabulations

\begin{tabular}{llcccc}
\hline Variables & $\begin{array}{l}\text { Number Average SR } \\
\text { of SMEs }\end{array}$ & $\begin{array}{c}\text { implementation } \\
\text { level }\end{array}$ & $\begin{array}{l}\text { Std. } \\
\text { dev. }\end{array}$ & $\begin{array}{l}\text { Average } \\
\text { sustainability/ } \\
\text { SR score }\end{array}$ & $\begin{array}{l}\text { Std. } \\
\text { dev. }\end{array}$ \\
\hline $\begin{array}{l}\text { Owner-managers with } \\
\text { degree level education }\end{array}$ & 36 & 2.06 & 0.94 & 83.76 & 19.27 \\
Owner-managers with no degree & 23 & 2.22 & 1.08 & 75.33 & 19.29 \\
SMEs with specific SR standards & 16 & 2.27 & 0.95 & 80.81 & 15.21 \\
(e.g., ISO certificates) & & & & & \\
SMEs with no SR standards & 43 & 2.12 & 1.01 & 80.35 & 21.11 \\
Exporting SMEs & 16 & 2.23 & 0.84 & 83.86 & 10.04 \\
Non-exporting SMEs & 43 & 2.13 & 1.05 & 79.22 & 22.05 \\
Medium-sized firms & 12 & 2.33 & 0.97 & 86.90 & 12.47 \\
Small firms & 47 & 2.11 & 1.00 & 78.84 & 20.77 \\
\hline
\end{tabular}

Table 8

Regression model 1 (where AvgLev is the dependent variable)

\begin{tabular}{ll} 
Variable & \\
\hline AvgSco & $0.024^{* * *}(0.007)$ \\
ResAge & $-0.012(0.011)$ \\
BusAge & $0.020(0.017)$ \\
dexp & $0.031(0.311)$ \\
dmed & $-0.213(0.387)$ \\
dstnd & $0.267(0.326)$ \\
ddeg & $-0.025(0.266)$ \\
$\mathrm{N}$ & 59 \\
Adjusted R2 & 0.163
\end{tabular}

$* \mathrm{p}<0.05 ; * * \mathrm{p}<0.01 ; * * \mathrm{p}<0.001$

*Standard errors in parenthesis 


\begin{tabular}{ll}
\hline Variable & \\
\hline AvgLev & $8.621^{* * *(2.380)}$ \\
ResAge & $0.246(0.212)$ \\
BusAge & $0.230(0.334)$ \\
dexp & $4.100(5.908)$ \\
dmed & $6.903(7.334)$ \\
dstnd & $-4.606(6.229)$ \\
ddeg & $5.548(5.010)$ \\
N & 59 \\
Adjusted R2 & 0.216 \\
\hline
\end{tabular}

$* \mathrm{p}<0.05 ; * * \mathrm{p}<0.01 ; * * \mathrm{p}<0.001$

*Standard errors in parenthesis

\subsection{Multiple regressions}

The two models used in this study are as follows:

$A v g L e v=\alpha 0+\beta 1($ ResAge $)+\beta 2($ BusAge $)+\beta 3($ AvgSco $)+\beta 4($ dmed $)$

$+\beta 5(\operatorname{dexp})+\beta 6($ dstnd $)+\beta 7($ ddeg $)+\varepsilon$

AvgSco $=\alpha 0+\beta 1($ ResAge $)+\beta 2($ BusAge $)+\beta 3($ AvgLev $)+\beta 4($ dmed $)$

$+\beta 5(\operatorname{dexp})+\beta 6($ dstnd $)+\beta 7($ ddeg $)+\varepsilon$

where

AvgLev average SR implementation level

AvgSco average sustainability/SR score.

$\alpha \quad$ constant

ResAge age of respondents

BusAge years in operation

dmed dummy variable for medium-sized firms

dexp dummy variable for exporting SMEs

dstnd dummy variable for SMEs with specific SR standards (e.g. ISO certificates)

ddeg dummy variable for owner-managers with degree level education

error term.

Both models were checked for possible interaction effects and multicollinearity. No evidence of interaction effects and multicollinearity was found. The VIF values for all independent variables are below 2.0 suggesting that there is no problem of multicollinearity. Although the cross tabulation (Table 7) shows that educational attainment of the SME owner-managers, business size and type have some minor impact 
on the average SR score and implementation level (as there are slight differences in values), the multiple regressions show no significant impact of such factors. Only the average sustainability/SR score and SR implementation level has a significant effect on each other ( $p$ value less than 0.05 in both models). The results indicate that the adjusted $\mathrm{R}$ squared for the two models used in the study are 0.16 and 0.22 respectively and the F-values are $2.62(\mathrm{p}>0.002)$ and $3.29(\mathrm{p}>0.005)$ respectively. This means that only $16 \%$ and $22 \%$ of the variation in the sustainability/SR score or average SR implementation level can be explained by the models. That is to say, the sustainable or socially responsible business practices of Bangladeshi manufacturing SMEs are not affected by their sizes, types or educational levels of their owner-managers, and there are other possible factors (which are not identified in this study) that might have more significant impact on SR activities.

\section{Discussion}

The findings of this study broadly highlight the so called 'attitude-behaviour' gap, which was already identified as being one of the major challenges faced by SME owner-managers in both developed and developing countries (Battisti and Perry, 2011; Cassells and Lewis, 2011). In other words, SME owner-managers do have a positive attitude towards SR, but, because of inherent limitations and external factors, they fail to convert this attitude into action. The findings also show how some of the owner-managers interviewed ascribe great importance to profit and demonstrate high levels of egoism; these factors, in turn, fuel the heightened cynicism that permeates their perception of SR (Au and Tse, 2001; Bhutta et al., 2008). However, one must be very careful in interpreting such cynicism, as it may not accurately and comprehensively reflect the owner-managers' personalities; rather, it could be a side-effect of the overall Bangladeshi business environment, which is plagued by problems such as corruption and lack of governmental support (see Azmat, 2008; Belal and Roberts, 2010).

Bangladeshi Manufacturing SMEs display a mix of strategic and moral reasons for their engagement in SR. The moral ones are related to personal passion and values (e.g., religious beliefs) and pertain to how businesses can deliver positive outcomes to society, whilst the strategic ones are geared to the improvement of financial results (van de Ven and Graafland, 2006). Almost all the surveyed SMEs donate money to charity, which improves their relationships with their local communities. So, although the owner-managers' religious beliefs initially motivate them to engage in philanthropic activities, they are ultimately swayed by the instrumental benefits of such engagements. Interestingly, this study reveals that SMEs do not consider stakeholder pressure to be a motivating factor to engage in SR as they believe that such pressures can easily be dealt with by bribes. This further reinforces the weak governance and corruption issues persistent in many lowincome developing countries (Demuijnck and Ngnodjom, 2013; Amaeshi et al., 2006).

Similar to those obtained by Vives (2006), Yu and Bell (2007), Demuijnck and Ngnodjom (2013), and Ramasobana and Fatoki (2014), the findings of this study reveal that the main barriers hindering the implementation of SR are corruption, misconceptions, lack of financial resources, and lack of external support. It is not surprising that Bangladeshi SMEs place a heightened emphasis on the lack of governmental support. Although the latest National Industrial Policy (2010) heavily 
emphasised the provision of support to SMEs with regard to SR implementation, many such companies do not even know where to find such support, which shows either that such government support facilities only exist on paper or that the dissemination channels of such facilities are ineffective in reaching their target audience. SR implementation is also being disrupted by the owner-managers' erroneous perceptions. As this study shows, many owner-managers do not consider environmental issues to be relevant to their businesses and still view philanthropy as the only form of SR. This study further highlights the fact that SMEs struggle to gain access to capital in Bangladesh, especially when seeking funding for the installation of sustainable technologies, which is usually a medium to long-term investment (Vives et al., 2005). Thus, there is the need to involve financial institutions in supporting SMEs with regard to their adoption of sustainable business practices.

Finally, corruption is identified as the biggest barrier to SR implementation in Bangladesh. As mentioned earlier, it is interesting to note that the owner-managers themselves do not view their own activities as being part of the cycle of corruption; rather, they are more prone to pointing the finger at what other parties are up to, which shows a tendency to 'pass the buck' among SME owner-managers in Bangladesh.

\subsection{Explanation of the SR implementation levels and SR/sustainability scores}

As reported earlier, this study reveals that Bangladeshi manufacturing SMEs score very high in $\mathrm{SR} /$ sustainability $(80.48 \%)$. This particular finding is inconsistent with others produced by this research. One possible reason for this could be that, despite the complete anonymity ensured, many of the owner-managers surveyed chose not to report any negative aspects of their businesses. Alternatively, it could be that, although the questions had been significantly tailored to the local culture, the participants failed to understand the SR related content. However, in terms of SR implementation levels, this study reveals some consistent and convincing findings. It finds that the Bangladeshi manufacturing SMEs have reached level 2 in terms of SR implementation. It may be said that the owner-managers implement SR in a fragmented manner, which means that, while they follow some aspects of SR, they ignore many more that do not conform to their personal motives. The survey findings also reveal a very low level of implementation in terms of community involvement and development. This is somewhat consistent with Azmat and Samaratunge (2009), who argued that microbusinesses in developing countries tend to isolate themselves from their local communities and focus on survival. Although, theoretically, there are clear differences between microbusinesses and SMEs, in a low-income developing country like Bangladesh (if not in all developing countries), indigenous businesses, irrespective of their size, are mostly owner-managed or controlled by family members. In this respect, one could legitimately argue that SMEs in Bangladesh are little more than 'big microbusinesses'. So, although the main focus of Azmat and Samaratunge's (2009) conceptual paper was on microbusinesses, to some extent, their argument is applicable to the current study, particularly because more than $70 \%$ of the sample SMEs are indigenous small manufacturing firms (see Table 3 ) that, as argued above, do not substantially differ from microbusinesses.

By contrast, the interviews revealed that SME owner-managers, in fact, do try to build relationships with their local communities through philanthropic activities. Such contradictory findings warrant further empirical investigation to clarify the issue. Finally, 
as shown by the regression models, this study fails to identify any significant influence of business size and type, and owner-manager educational attainment on the socially responsible or sustainable practices of manufacturing SMEs in Bangladesh, which suggests that SME engagement in SR is possibly influenced by other external factors, which may include the availability of bank loans, training and other facilities, tax exemptions, etc.

\section{Contributions and implications}

The purpose of this study was to explore the extent to which manufacturing SMEs in Bangladesh implement SR/sustainability into their regular business activities. The study also reveals the key motivations of Bangladeshi owner-managers and the barriers and challenges they face to engage in sustainable and socially responsible business practices.

The study makes two important contributions to the small business sustainability/SR literature. Although this literature has now matured considerably, its predominant focus, to date, remains on SMEs based in developed countries (Jamali et al., 2015). Very few empirical studies have been carried out in developing-country contexts, and even a large chunk of these has looked at SMEs based in middle-income developing countries, whilst the representation of other developing countries, low-income ones in particular, is very minimal. In this respect, this study makes an important empirical contribution by looking at the issue of SR/sustainability from the perspective of SME owner-managers based in Bangladesh, a low-income developing country. In addition, the exclusive reliance on quantitative survey data of past empirical studies in developing-country contexts limited most of them to generating only the most basic (descriptive) comprehension of SME engagement in sustainable and socially responsible activities; conversely, this study's mixedmethod research design enables it to provide a more nuanced understanding of the latter.

The second contribution is a methodological one. Drawing on the four key elements of ISO 26000, this paper develops a context-specific and culturally-relevant tool to measure the involvement of Bangladeshi manufacturing SMEs in sustainable and socially responsible business practices. By doing so, it specifically responds to Spence and Painter-Morland's (2010a, p.333) call on the subject. The tool developed in this study is unique and was not used by any researcher in the past. It can be hitherto used to study sustainability related issues in SMEs based in other low-income developing countries. Finally, although the ISO 26000 Guidance has been criticised for being broad and over-optimistic (Schwartz and Tilling, 2009; Watkins and Belinky, 2011; Ward, 2011; Roberts, 2010), this study shows that it can still be adapted to fit the reality of SMEs based in low-income developing countries.

This study's overall findings indicate that manufacturing SMEs in Bangladesh, like those in other developing and least developed countries, are primarily profit-driven. Their prime focus is on surviving by maximising profits, while societal and other national concerns are secondary. Although there is widespread awareness of the facts that SR occurs before profit and that responsible business behaviours pay off in the long run, all decisions made by the owner-managers must lead to profits. Interestingly, Bangladeshi SME owner-managers tend to join the chorus; most of them reported that they are part of a culture of corruption in which there is no place for SR. This further reinforces the issue of SMEs from developing and emerging countries being disadvantaged by a number of 
constraints such as corruption and lack of external support [Spence and Painter-Morland, (2010b), p.8]. The state of SR implementation in Bangladesh could also be compared with what Visser (2014) called defensive and charitable CSR, which is characterised by both greed and philanthropy. This study's findings also present obvious advantages to policy-makers in Bangladesh and other similar countries in which the existing approaches to the promotion of voluntary SR standards often rely on a traditional command-and-control structure (Selim, 2011); one that ignores the micro-level challenges faced by SME owner-managers, who run their businesses in informal or semi-formal settings (Dasgupta, 2000; Lund-Thomsen et al., 2014). In particular, the very low levels of trust placed by most SME owner-managers in government agencies and support services are very alarming. It indicates the absence of legitimacy held by the sustainability stakeholders responsible for promoting voluntary SR standards in Bangladesh in the eyes of SME owner-managers. The lack of knowledge and awareness of the support services available to SMEs further signal that the existing governmental approaches to the promotion of sustainability in Bangladesh are largely ineffective. Therefore, in order to truly materialise the sustainability agenda or to implement key elements of voluntary SR guidance, such as ISO 26000, the government must take a bottom-up approach whereby it would develop awareness of sustainability and its related issues before initiating implementation efforts.

Furthermore, this study reveals the tendency, amongst the Bangladeshi SME owner- managers, to justify neglecting their responsibilities and taking irresponsible actions by means of a logic that is only applicable to them. This could be seen as a by-product of the country's broader socio-economic environment, characterised by pervasive corruption and poverty (Azmat, 2008). Such findings have significant social implications and could not simply be taken for granted. They imply high levels of social anomie in low-income developing societies; these, obviously, have negative effects on the ways in which people do business and judge socially responsible and sustainable business practices. The so called win-win promises embedded in many international SR standards or even in national sustainability policies cannot be effective in such environments. Thus, the government needs to design innovative policies that would allow SMEs to profit only in sustainable and socially responsible ways. Currently, as the findings of this study indicate, the business case for irresponsibility or unsustainability is more powerful in Bangladesh than that for sustainability (the win-win case). This situation needs to be reversed if any real improvements are to be made.

Whilst this paper has provided fruitful insights into the sustainable and socially responsible practices of manufacturing SMEs in a low-income developing country context, admittedly, it does present some limitations. The findings were gleaned from SMEs based in a single location in Bangladesh (i.e., Dhaka). A larger sample drawn from different parts of the country would have better supported the research aim. Nevertheless, the sample firms were selected from a variety of SME clusters, which increased the acceptability of the findings. An additional limitation is that, due to time restrictions, no pilot study was carried out; consequently, some inconsistent findings were generated. More large-scale studies are required to empirically test the measurement technique used in this study. It is also necessary for future studies to use pilot surveys to test the practical applicability of the questionnaire.

Finally, is SR a doable reality or luxury? The answer to this question, as this research amply justifies, is that SR is indeed a luxury for the indigenous SMEs in Bangladesh. This research, however, is the very first of its kind in the CSR literature that develops 
instruments to assess the socially responsible or sustainable practices of SMEs in a meaningful way. The intention was not to make any recommendation, rather it is hoped that the inputs obtained from this study can constitute the ground for a further and deepened analysis on the relationship between SR and SMEs in the Bangladeshi business context.

\section{References}

Adams, J., Khan, H.T. and Raeside, R. (2007) Research Methods for Business and Social Science Students, SAGE Publications, London.

Ahmed, S. and Rahman, A. (2012) The Current State and Future Directions for Small and Medium Manufacturing Enterprises (SME) in the Manufacturing Sector in Bangladesh, Policy Research Institute of Bangladesh (PRI), Dhaka.

Altheide, D.L. (1987) 'Reflections: ethnographic content analysis', Qualitative Sociology, Vol. 10, No. 1, pp.65-77.

Amaeshi, K.M., Adi, B.C., Ogbechie, C. and Amao, O.O. (2006) 'Corporate social responsibility in Nigeria', Journal of Corporate Citizenship, Winter, Vol. 24, pp.83-99.

$\mathrm{Au}$, A.K. and Tse, A.C. (2001) 'Marketing ethics and behavioral predisposition of Chinese managers of SMEs in Hong Kong', Journal of Small Business Management, Vol. 39, No. 3, pp.272-278.

Ávila, L.V., Hoffmann, C., Corrêa, A.C., Rosa Gama Madruga, L.R., Schuch Júnior, V.F., Júnior, S. and Zanini, R.R. (2013) 'Social responsibility initiatives using ISO 26000: an analysis from Brazil', Environmental Quality Management, Vol. 23, No. 2, pp.15-30.

Azmat, F. (2008) 'Understanding responsible entrepreneurship of micro-businesses in Bangladesh', ASAA 2008: Proceedings of the Asian Studies Association of Australia 17th Biennial Conference: Is this the Asian Century in Melbourne, Australia, 2008, Monash University, Victoria, pp.1-15.

Azmat, F. and Samaratunge, R. (2009) 'Responsible entrepreneurship in developing countries: understanding the realities and complexities', Journal of Business Ethics, Vol. 90, No. 3, pp.437-452.

Bangladesh Small and Cottage Industries Corporation (BSCIC) (2013) Statistics on SCI [online] $\mathrm{http} / /$ www.bscic.gov.bd/index.php?option=com_content\&view=article\&id=65\&Itemid=128\& lang=en (accessed 4 June 2014).

Battisti, M. and Perry, M. (2011) 'Walking the talk? Environmental responsibility from the perspective of small-business owners', Corporate Social Responsibility and Environmental Management, Vol. 18, No. 3, pp.172-185.

BBS (2012) Foreign Trade Statistics [online] http://www.sid.gov.bd/statistics/foreigntrade- statistics-january2012 (accessed 4 June 2014).

Begum, F.A. (2013) Proposed SME Policy Strategy 2013: A Critique [online]

http://www.thefinancialexpress-bd.com/old/index.php?ref=

MjBfMDNfMTRfMTNfMV8yN18xNjMxMDI (accessed 14 March 2014).

Belal, A.R. and Cooper, S. (2011) 'The absence of corporate social responsibility reporting in Bangladesh', Critical Perspectives on Accounting, Vol. 22, No. 7, pp.654-667.

Belal, A.R. and Momin, M. (2009) 'Corporate social reporting (CSR) in emerging economies: a review and future direction', Research in Accounting in Emerging Economies, Vol. 9, No. 2, pp.119-143.

Belal, A.R. and Roberts, R.W. (2010) 'Stakeholders' perceptions of corporate social reporting in Bangladesh', Journal of Business Ethics, Vol. 97, No. 2, pp.311-324.

BGMEA (2013) Trade Information [online] http://bgmea.com.bd/home/pages/TradeInformation\#. UneD7Pnp3_F (accessed 4 June 2014). 
Bhutta, M.K.S., Rana, A.I. and Asad, U. (2008) 'Owner characteristics and health of SMEs in Pakistan', Journal of Small Business and Enterprise Development, Vol. 15, No. 1, pp.130-149.

Cassells, S. and Lewis, K. (2011) 'SMEs and environmental responsibility: do actions reflect attitudes?', Corporate Social Responsibility and Environmental Management, Vol. 18, No. 3, pp.186-199.

Creswell, J.W. (2009) Research Design: Qualitative, Quantitative, and Mixed Methods Approaches, 3rd ed., Sage, London.

Dasgupta, N. (2000) 'Environmental enforcement and small industries in India: reworking the problem in the poverty context', World Development, Vol. 28, No. 5, pp.945-967.

Demuijnck, G. and Ngnodjom, H. (2013) 'Responsibility and informal CSR in formal cameroonian SMEs', Journal of Business Ethics, Vol. 112, No. 4, pp.653-665.

Hasan, M.N. and Islam, M.S. (2015) 'Sustainable and socially responsible business in Bangladesh (country chapter)', in Visser, W. (Ed.): The World Guide to Sustainable Enterprise: Volume 2 (Asia Pacific), Forthcoming in Spring 2016, Greenleaf Publishing, Sheffield.

Hsieh, H.F. and Shannon, S.E. (2005) 'Three approaches to qualitative content analysis', Qualitative Health Research, Vol. 15, No. 9, pp.1277-1288.

International Organization for Standardization (ISO) (2010) Guidance on Social Responsibility, ISO/FDIS 26000: 2010 (E), Final Draft, ISO, Geneva.

Isaksson, R., Johansson, P. and Fischer, K. (2010) 'Detecting supply chain innovation potential for sustainable development', Journal of Business Ethics, Vol. 97, No. 3, pp.425-442.

Islam, M.A. and Deegan, C. (2008) 'Motivations for an organisation within a developing country to report social responsibility information: evidence from Bangladesh', Accounting, Auditing \& Accountability Journal, Vol. 21, No. 6, pp.850-874.

Islam, S., Reed, R. and Poole, P. (2013) International Standard Social Responsibility (Implementing ISO 26000 in Bangladesh), Canada Bangladesh Chamber of Commerce and Industry (CanCham), Dhaka.

ISO website (no date a) ISO 14000 - Environmental Management [online]

http://www.iso.org/iso/iso14000 (accessed 24 August 2014).

ISO website (no date b) ISO 9000 - Quality management [online] http://www.iso.org/iso/iso_9000 (accessed 24 August 2014).

Jamali, D., Lund-Thomsen, P. and Jeppesen, S. (2015) 'SMEs and CSR in developing countries', Business \& Society, Online first, forthcoming.

Jamali, D., Zanhour, M. and Keshishian, T. (2009) 'Peculiar strengths and relational attributes of SMEs in the context of CSR', Journal of Business Ethics, Vol. 87, No. 3, pp.355-377.

Jenkins, H. (2004) 'A critique of conventional CSR theory: an SME perspective', Journal of General Management, Vol. 29, No. 4, pp.55-75.

Jeppesen, S., Kothuis, B. and Tran, A.N. (2012) Corporate Social Responsibility and Competitiveness for SMEs in Developing Countries: South Africa and Vietnam, Agence Française de Développement, Paris.

Khan, A., Muttakin, M.B. and Siddiqui, J. (2013) 'Corporate governance and corporate social responsibility disclosures: evidence from an emerging economy', Journal of Business Ethics, Vol. 114, No. 2, pp.207-223.

Kivuitu, M., Yambayamba, K. and Fox, T. (2005) 'How can corporate social responsibility deliver in Africa? Insights from Kenya and Zambia', Perspectives on Corporate Responsibility for Environment and Development, No. 3, pp.1-4, Briefing Paper Published by International Institute for Environment and Development, London.

Lin, C.Y. and Ho, Y.H. (2011) 'Determinants of green practice adoption for logistics companies in China', Journal of Business Ethics, Vol. 98, No. 1, pp.67-83.

Luetkenhorst, W. (2004) 'Corporate social responsibility and the development agenda', Intereconomics, Vol. 39, No. 3, pp.157-166. 
Lund-Thomsen, P., Jamali, D. and Vives, A. (2014) 'CSR in SMEs: an analysis of donor-financed tools', Social Responsibility Journal, Vol. 10, No. 4, pp.602-619.

Merriam, S.B. (2014) Qualitative Research: A Guide to Design and Implementation, John Wiley \& Sons, Inc, San Francisco.

Mintoo, A.A. (2006) 'SMEs in Bangladesh', CACCI Journal, Vol. 1, No. 1, pp.1-19.

Miyan, S.K. (2011) 'A picture of corporate social responsibility in Bangladesh', International Journal of Governance, Vol. 1, No. 1, pp.1-12.

Momin, M.A. and Hossain, M. (2011) 'Corporate social responsibility (CSR) reporting by multinational corporations (MNCs) subsidiaries in an emerging country', Corporate Ownership and Control, Vol. 9, No. 1, pp.96-114.

Murillo, D. and Lozano, J.M. (2006) 'SMEs and CSR: an approach to CSR in their own words',

Journal of Business Ethics, Vol. 67, No. 3, pp.227-240.

Nasrullah, N.M. and Rahim, M.M. (2014) 'CSR in private enterprises in developing countries', Evidences from the Ready-Made Garments Industry in Bangladesh, Springer International Publishing, Switzerland.

National Industrial Policy (2010) Ministry of Industries, Government of the People's Republic of Bangladesh, Dhaka [online] http://www.smef.org.bd/v2/smef_download/government_policies

/Industrialpolicy_revised2010Eng.pdf (accessed June 3 2014).

National Sustainable Development Strategy (NSDS) (2013) Planning Commission - Ministry of Planning,

Government of the People's Republic of Bangladesh, Dhaka [online] http://www.plancomm.gov.bd/wpcontent/uploads/2013/09/National-Sustainable- Development-Strategy.pdf (accessed 3 June 2014).

Pallant, J. (2007) SPSS Survival Manual: A Step by Step Guide to Data Analysis Using SPSS, $\quad 3 r d$ ed., Ligare Book Printer, Australia.

Panda, S. and Dash, S. (2014) 'Constraints faced by entrepreneurs in developing countries: a review and assessment', World Review of Entrepreneurship, Management and Sustainable Development, Vol. 10, No. 4, pp.405-421.

Perera, O. (2008) How Material is ISO 26000 Social Responsibility to Small and Medium-sized Enterprises (SMEs)?, International Institute for Sustainable Development (IISD), Manitoba.

Perry, P. (2013) 'Garments without guilt? A case study of sustainable garment sourcing in Sri Lanka', in Gardetti, M.A. and Torres, A.L. (Eds.): Sustainability in Fashion and Textiles, pp.294-307, Greenleaf Publishing, Sheffield.

Perry, P., Wood, S. and Fernie, J. (2015) 'Corporate social responsibility in garment sourcing networks: factory management perspectives on ethical trade in Sri Lanka', Journal of Business Ethics, Vol. 130, No. 3, pp.737-752.

Ramasobana, A.M. and Fatoki, O. (2014) 'An investigation into the business social responsibility of micro enterprises in South Africa', Mediterranean Journal of Social Sciences, Vol. 5, No. 3, pp.283-289.

Raynard, P. and Forstater, M. (2002) Corporate Social Responsibility: Implications for Small and Medium Enterprises in Developing Countries, U.N. Industrial Development Organization, Vienna.

Roberts, J.M. (2010) How Corporate Social Responsibility (ISO 26000) Mandates Undermine Free Markets, Backgrounder No. 2409, The Heritage Foundation, Washington, DC.

Rouf, A.M. (2011) 'The corporate social responsibility disclosure: a study of listed companies in Bangladesh', Business and Economics Research Journal, Vol. 2, No. 3, pp.19-32.

Roy, A., Vyas, V. and Jain, P. (2013) 'SMEs motivation. Skimming \& scanning', SCMS Journal of Indian Management, Vol. 10, No. 1, pp.11-22.

Schwartz, B. and Tilling, K. (2009) 'ISO-lating' corporate social responsibility in the organizational context: a dissenting interpretation of ISO 26000', Corporate Social Responsibility and Environmental Management, Vol. 16, No. 5, pp.289-299. 
Selim, S. (2011) Ecological Modernisation and Environmental Compliance: The Garments Industry in Bangladesh, Routledge, London.

Singh, K. (2007) Quantitative Social Research Methods, Sage, London.

SME Foundation (2013) SME clusters in Bangladesh, Small and Medium Enterprise Foundation, Dhaka.

Southwell, C. (2004) 'Engaging SMEs in community and social issues', in Spence, L.J., Habisch, A. and Schmidpeter, R. (Eds.): Responsibility and Social Capital: The World of Small and Medium Sized Enterprises, pp.96-111, Palgrave MacMillan, Hampshire.

Spence, L. and Rutherfoord, R. (2003) 'Small business and empirical perspectives in business ethics: Editorial', Journal of Business Ethics, Vol. 47, No. 1, pp.1-5.

Spence, L.J. and Painter-Morland, M. (2010a) 'Conclusion: the road ahead for research on ethics and SMEs', in Spence, L.J. and Painter-Morland, M. (Eds.): Ethics in Small and Medium Sized Enterprises, pp.333-338, Springer Verlag, Chicago.

Spence, L.J. and Painter-Morland, M. (2010b) 'Introduction: global perspectives on ethics in small and medium sized enterprises', in Spence, L.J. and Painter-Morland, M. (Eds.): Ethics in Small and Medium Sized Enterprises, pp.1-9, Springer Verlag, Chicago.

Spence, M., Gherib, J.B.B. and Biwolé, V.O. (2011) 'Sustainable entrepreneurship: is entrepreneurial will enough? A north-south comparison', Journal of Business Ethics, Vol. 99, No. 3, pp.335-367.

Tang, Z. and Tang, J. (2015) 'The influence of stakeholder-firm power difference on corporate social responsibility of Chinese small and medium-sized enterprises', World Review of Entrepreneurship, Management and Sustainable Development, Vol. 11, No. 4, pp.414-428.

Tang, Z., Tang, J., Marino, L.D., Zhang, Y. and Li, Q. (2010) 'An investigation of entrepreneurial orientation and organisational strategies in Chinese SMEs', World Review of Entrepreneurship, Management and Sustainable Development, Vol. 6, No. 3, pp.206-223.

Transparency International (2013) Corruption Perceptions Index 2013 [online]

http://cpi.transparency.org/cpi2013/results/\#myAnchor1 (accessed 11 May 2014).

Tsoi, J. (2010) 'Stakeholders' perceptions and future scenarios to improve corporate social responsibility in Hong Kong and Mainland China', Journal of Business Ethics, Vol. 91, No. 3, pp.391-404.

Uygur, S. (2009) 'The Islamic work ethic and the emergence of Turkish SME owner-managers', Journal of Business Ethics, Vol. 88, No. 1, pp.211-225.

van de Ven, B. and Graafland, J. (2006) 'Strategic and moral motivation for corporate social responsibility' Journal of Corporate Citizenship, Summer, Vol. 21, pp.111-123.

Visser, W. (2014) CSR 2.0: Transforming Corporate Sustainability and Responsibility, Springer, London.

Vives, A. (2006) 'Social and environmental responsibility in small and medium enterprises in Latin America', Journal of Corporate Citizenship, Spring, Vol. 21, pp.39-50.

Vives, A., Corral, A. and Isusi, I. (2005) Responsabilidad Social de la Empresa en las PyMEs de Latinomérica, Banco Interamericano de Desarrollo, Washington DC [online] http://www.cumpetere.com/Documents/RSE\%20en\%20PyMEs.pdf (accessed 6 May 2014).

Walliman, N. (2006) Social Research Methods, Sage, London.

Ward, H. (2011) 'The ISO 26000 international guidance standard on social responsibility: implications for public policy and transnational democracy', Theoretical Inquiries in Law, Vol. 12, No. 2, pp.665-718.

Watkins, M. and Belinky, A. (2011) 'ISO 26000 implementation - a Brazilian perspective', in Henriques, A. (Ed.): Understanding ISO 26000 - A Practical Approach to Social Responsibility, pp.79-90, British Standards Institution, London.

Willard, B. (2005) The Next Sustainability Wave: Building Boardroom Buy-in, New Society Publishers, Gabriola Island. 
Willard, B. (2009) The Sustainability Champion's Guidebook: How to Transform Your Company, New Society Publishers, Gabriola Island.

Willard, B. (2012) The New Sustainability Advantage: Seven Business Case Benefits of a Triple Bottom Line, New Society Publishers, Gabriola Island.

World Bank (2012) Worker in the Informal Economy [online] http://web.worldbank.org/WBSITE/ EXTERNAL/TOPICS/EXTURBANDEVELOPMENT/EXTLED/0,,contentMDK:20309607

menuPK:341145 pagePK:148956 piPK:216618 theSitePK:341139,00.html (accessed 7 May 2014).

$\mathrm{Yu}$, J. and Bell, J.N.B. (2007) 'Building a sustainable business in China's small and medium-sized enterprises (SMEs)', Journal of Environmental Assessment Policy and Management, Vol. 9, No. 1, pp.19-43.

\section{Notes}

1 The terms 'sustainability' and 'social responsibility (SR)' are used interchangeably throughout this paper.

2 The informal sector or economy refers to activities and income that are partially or fully outside government regulation, taxation, and observation. The main attraction of the informal sector is financial. This type of activity allows employers, paid employees, and the selfemployed to increase their take-home earnings or reduce their costs by evading taxation and social contributions. The informal sector is a pervasive and persistent economic feature of most developing economies, contributing significantly to employment creation, production, and income generation (World Bank, 2012).

3 Bangladesh Small and Cottage Industries Corporation.

4 There are seven key elements of SR outlined in the ISO 26000 guidance. However, this research used only four of them (i.e. labour practices, the environment, consumer issues, and community involvement and development) as benchmarks of sustainability and SR. The rests are not considered as relevant for SMEs in developing countries. The Guidance itself suggested [ISO, (2010), p.8] to use it sensibly as not all issues outlined will be relevant for all types of businesses.

5 Implementation levels were disclosed by the SME owner-managers themselves after the answers provided on different SR-related issues.

6 Some of them also refused to fill the survey questionnaire for the reason that environment and consumer issues had nothing to do with them. Many apparently left these two sections empty, which forced the researcher to exclude those questionnaires from the study.

7 ISO 9001:2008 sets out the criteria for a quality management system and is the only standard in the family that can be certified to (although this is not a requirement) (ISO website, no date b).

8 SO 14001:2004 sets out the criteria for an environmental management system and can be certified to (ISO website, no date a).

9 Calculated in percentage. See Table 1 for details of how these scores were calculated.

10 Calculated on a level 0 to level 4 scale. See Table 2 for details of how SR implementation levels were calculated. 


\section{Appendix}

\section{Survey questionnaire}

\section{Section 1}

Enterprise information

Main product(s);

2 Main markets:

b

c

Local (community based)

National

Global (export)

3 Years in operation: years

4 Type of organisation:

$\begin{array}{ll}\text { a } & \text { Sole proprietorship } \\ \text { b } & \text { Limited company } \\ \text { c } & \text { Partnership } \\ \text { d } & \text { Family enterprise } \\ \text { e } & \text { Other (Please specify): }\end{array}$

5 Which of the following industries best describes the sector your company is operating? Please circle only one.

Knitwear and ready-made garments (RMG)

b

Leather making and leather goods

c Plastics and other synthetics

d Handloom and specialised textiles e

Handicraft

Light engineering and metal working

g

Other. Please specify:

6 Number of employees:

7 Do you have any certifications according to any standards of social responsibility or sustainability such as ISO standards or any other government certifications?
a Yes, please mention certificate name/title
b No

Section 2

\section{Respondent information}

1 Position in the

business: a Owner

b Partner 
c Manager

Other (Please specify):

Age of respondent:

3 Gender:

a Male

b

Female

4 Highest level of education completed:

a Primary

b Secondary (S.S.C.)

c Higher secondary (H.S.C)

d Bachelor's (honours, BBA, BSc) e

Master's (MBA, MSc)

Other (Please specify):

\section{Section 3}

\section{Measuring the level of socially responsible and/or sustainable business practices}

1 Labour practices

\begin{tabular}{lr}
\hline Questions & $\begin{array}{r}\text { Yes/no/not } \\
\text { applicable }\end{array}$ \\
\hline
\end{tabular}

Employment and employment relationships

Ensure equal opportunities for all workers and not discriminate either directly or indirectly in any labour practice

Protect personal data and privacy of the workers

Never seek any benefit from unfair, exploitative or abusive labour practices both of own company and of its partners, suppliers or subcontractor

Conditions of work and social protection

Working conditions comply with national laws and are consistent with applicable international labour standards

Respect the family responsibilities of the workers and help maintaining a proper work-life balance (e.g. by providing reasonable working hours, parental leave)

Compensate workers for overtime in accordance with laws, regulations or collective agreements

Health and safety at work

Provide the safety equipment needed (e.g. personal protective equipment) for the prevention of occupational injuries, diseases and accidents

Provide adequate training to all personnel on all health and safety related matters 
2 The environment

\begin{tabular}{lr}
\hline Questions & $\begin{array}{l}\text { Yes/no/not } \\
\text { applicable }\end{array}$ \\
\hline
\end{tabular}

Discharge of effluent

Chimney/machinery/generator exhaust is free of smoke

Effluents are treated properly by effluent treatment plant (ETP) before discharge and always achieve maximum standards

Percentage of waste materials is minimum

ETP always compliant with government standard Use of

natural resources

Raw materials are used efficiently so that non-product output (NPO) is minimised Materials are from renewable sources

Use of energy

Records of electricity use are kept and electricity use is minimised

Energy saving bulbs such as T5 fluorescent tubes are used to minimise energy consumption

Generators are maintained properly and efficiently Use of

water:

Company has access to safe and reliable supplies of drinking water

Flow meters record water consumed and effluent discharged to minimise water usage

The factory takes action to minimise wastage of water and reuse water as much as possible

Recycling waste products

The factory has a waste disposal contract

The percentage of re-used waste product is significant Conversion into energy saving factory

Solar power and wind generated electricity are in use Use special meter or device to reduce electricity wastage

Transportation

All company vehicles are run on compressed natural gas (CNG) All

company vehicles are maintained properly 


\section{Consumer issues}

\begin{tabular}{ll}
\hline Questions & $\begin{array}{l}\text { Yes/no/not } \\
\text { applicable }\end{array}$ \\
\hline
\end{tabular}

Fair marketing

Company do not engage in any practice that is deceptive, misleading, fraudulent and ambiguous (including omission of critical information) when communicating with consumers

Protecting consumers' health and safety

Provide products and services that are safe for users and other persons, their property, and the environment

Avoid using any harmful chemicals in product development or in product storing Consumer service

Offer high quality products and services, at affordable prices Review

complaints and improve practices in response to complaints

4 Community involvement and development

Questions

Owner-manager regularly participates in local associations as possible and appropriate, with the objective of contributing to the public good and the development goals of the community

Owner-manager maintains a transparent relationship with local government officials and political representatives (free from bribery or improper influence)

Create employment opportunities in the community by hiring local people at work

Consider giving preference to local suppliers of products or services and contributing to local supplier development where possible

Seek to eliminate any negative environmental/social impacts of any production process, product or service provided by the company

Owner-manager actively engages in charitable activities and donates money to the disadvantaged people

**This research intends to measure socially responsible and sustainable practices of Bangladeshi SMEs on a level zero to level four scale. The definition of the five levels is shown below:

Level 4:

Integrated into company strategies and culture

Level 3:

Full implementation at all levels in the company

Level 2:

Some evidence of implementation

Level 1:

Policy exists only in writing

Level 0:

Pre-compliance stage - no implementation 
5 Based on your answers to the above questions (questions 1 to 4, Section 3), how would you state your company's level of implementation in the following four categories of social responsibility? Please refer to the above section for definition of each level.

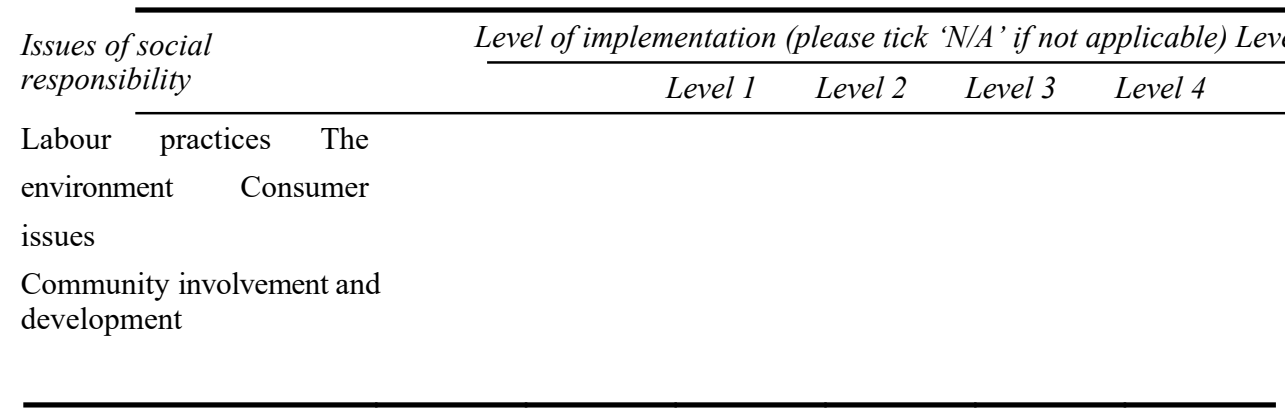

\section{Section 4}

\section{Drivers and barriers to implementing socially responsible business practices}

1 What would be the main reasons to implement sustainable and socially responsible practices in your company? Circle all that apply.

a Stakeholders pressure (buyers, NGOs, government, consumer pressure groups, etc.)

b To comply with domestic and international legislation on social responsibility (or CSR)

c Improve relationship with the community and increase overall reputation of the business

d Customer expectations

e Religious and cultural beliefs $\mathrm{f}$

Ethical and personal values

Others. Please mention:

2 What are the main obstacles that hinder the adoption of socially responsible and sustainable practices in your enterprise? Circle statements that match best.

a Lack of time and human resources

b Lack of efficient institutions to assist and implement social responsibility c

Monitoring and auditing costs (lack of finance)

Complex procedures of measurement and reporting

No immediate financial gain

Lack of understanding of the issue and its possible benefits

Lack of governmental support

There are activities that are not related to the company

The business does not have any environmental impact

Corruption of the regulatory authorities (bribery, misuse of power, etc.)

Others (Please explain): 


\section{Section 5}

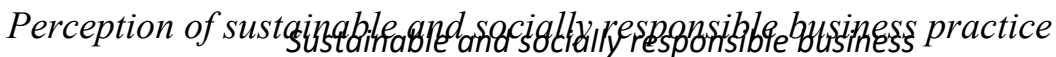

1 Considering the context of your business and Bangladesh in general, how would you define the term 'social responsibility'? Circle all that apply.

a Donating money to charitable organisations, hospitals, religious or educational institutions

b Meeting legislative requirements

c Minimising all types of negative environmental and social impact of the business

d Ensuring health and safety of the workers e Participating in community development Producing/selling harmless products and services to the consumers $g$ All of the above

h One of the above, as social responsibility is not a 'commercially viable' option for SMEs in Bangladesh

i

Other. Please specify:

2 Which of the following issues of social responsibility is appropriate for your business? Circle all that apply.

a Organisational governance $b$ Human rights

c Labour practices dThe

environment

e

Fair operating practices $f$

Consumer issues

g

Community involvement and development $\mathrm{h}$

None of the above

3 If the employees/workers of a factory do not use protective clothing (though it is required of them) would you regard that factory as socially responsible?

a Yes

b No

4 Suppose, a factory pollutes the local water supply by disposing of its chemical waste into the pond but the factory also gives money to the poor of the community each year, is it a socially responsible factory?
a Yes
b No 